(2) Open Access Full Text Article

\title{
Systematic review and meta-analysis of the benefit of celecoxib in treating advanced non-small-cell lung cancer
}

This article was published in the following Dove Press journal:

Drug Design, Development and Therapy

\author{
Lilan $\mathrm{Yi}^{*}$ \\ Wei Zhang* \\ Hongman Zhang \\ Jie Shen \\ Jingwen Zou \\ Peng Luo \\ Jian Zhang
}

Department of Oncology, Zhujiang Hospital, Southern Medical University, Guangzhou, Guangdong, People's Republic of China

*These authors contributed equally to this work
Correspondence: Peng Luo; Jian Zhang Department of Oncology, Zhujiang Hospital, Southern Medical University, 253 Industrial Avenue, Guangzhou 510282, Guangdong, People's

Republic of China

$\mathrm{Tel}+8613925091863$

Fax +862061643888

Email luopeng@smu.edu.cn; blacktiger@139.com
Background: The clinical benefit of a selective cyclooxygenase-2 inhibitor, celecoxib, combined with anticancer therapy in advanced non-small-cell lung cancer (NSCLC) remains unclear. A meta-analysis was performed to address the efficacy and safety of celecoxib in patients with advanced NSCLC.

Materials and methods: Three databases, including PubMed, EMBASE, and the Cochrane Library, were systematically searched for available literature until March 1, 2018. Data on tumor response rates, one-year survival, overall survival, progression-free survival, and toxicities were extracted from the included randomized clinical trials. Subgroup analysis was carried out according to the line of treatment. Review Manager 5.3 software was applied to conduct the meta-analysis. Results: A total of 7 randomized controlled trials involving 1,559 patients with advanced NSCLC were enrolled for analysis. The pooled overall response rate (ORR) of celecoxib added to systemic therapy was not significantly improved (risk ratio $[\mathrm{RR}]=1.14,95 \% \mathrm{CI}=0.96-1.35$, $P=0.13$ ). Additionally, no differences were observed between the celecoxib and placebo groups regarding 1 -year survival $(\mathrm{RR}=0.99,95 \% \mathrm{CI}=0.88-1.12, P=0.91)$. Subgroup analysis showed that adding celecoxib to the first-line treatment significantly improved the ORR ( $R R=1.21$, $95 \% \mathrm{CI}=1.01-1.44, P=0.04)$ and partial response rate $(\mathrm{RR}=1.26,95 \% \mathrm{CI}=1.01-1.58, P=0.04)$. The aggregated Kaplan-Meier analysis found no significant difference between celecoxib and placebo regarding the 5-year overall survival (median, 12.9 vs 12.5 months, $P=0.553$ ) and 5-year progression-free survival (median, 7.4 vs 7.2 months, $P=0.641$ ). The increased RR of leukopenia $(\mathrm{RR}=1.25,95 \% \mathrm{CI}=1.03-1.50)$ and thrombocytopenia $(\mathrm{RR}=1.39,95 \% \mathrm{CI}=1.11-1.75)$ indicated that celecoxib increased hematologic toxicities (grade $\geq \mathrm{III}$ ). However, celecoxib did not increase the related risks of thrombosis or embolism $(\mathrm{RR}=1.26,95 \% \mathrm{CI}=0.66-2.39)$ and cardiac ischemia ( $\mathrm{RR}=1.16,95 \% \mathrm{CI}=0.39-3.44)$.

Conclusion: Celecoxib had no benefit on survival indices for advanced NSCLC but improved the ORR of first-line treatment. Additionally, celecoxib increased the rate of hematologic toxicities without increasing the risk of cardiovascular events.

Keywords: celecoxib, non-small-cell lung cancer, NSCLC, systematic review, meta-analysis

\section{Introduction}

Globally, lung cancer is a serious health problem. This disease has become the leading cause of cancer death in men and the second leading cause of cancer death (after breast cancer) in women worldwide. ${ }^{1}$ It is estimated that there will be $>230,000$ new cases and $>150,000$ deaths in the United States in 2018. ${ }^{2}$ Non-small-cell lung cancer (NSCLC) is the most common subtype, accounting for $\sim 80 \%-85 \%$ of all lung cancer cases. ${ }^{3}$ More than $50 \%$ of newly diagnosed NSCLC patients have advanced 
stage (IIIB or IV) disease and have, therefore, lost the opportunity for early surgical treatment. ${ }^{4}$ EGFR tyrosine kinase inhibitors (TKIs) have a significant effect in the treatment of advanced NSCLC patients, but the efficacy is limited to EGFR wild-type patients..$^{5}$ External radiotherapy is often accompanied by many complications, such as radiation pneumonia, esophagitis, and bone marrow depression. In addition, the radiation dose is limited by the complications of normal tissue and important organs in the surrounding area. ${ }^{6,7}$ Platinum-based chemotherapy is the cornerstone of treatment for advanced NSCLC patients who are unable to be cured. However, traditional chemotherapy is not ideal for tumor control of inoperable patients, and the median overall survival (OS) is still not $>15$ months. ${ }^{8,9}$ Furthermore, the development of chemotherapy has reached a bottleneck for patients with advanced NSCLC. ${ }^{10}$ Accordingly, new treatment strategies are urgently needed.

Accumulating evidence has demonstrated a relationship between cancer and inflammation and has shown that inflammation in the tumor microenvironment has a tumorpromoting effect. ${ }^{11,12}$ At present, 1 target for inhibiting lung cancer-related inflammation is cyclooxygenase-2 (COX-2), an enzyme connected to prostaglandin generation and involved in pathological processes, such as the inflammation and cancer. Overexpression of COX-2 is common in NSCLC and is associated with a poor prognosis. ${ }^{13-17}$ Preclinical studies indicated that COX-2 may be a suitable target for antitumor treatment of NSCLC. ${ }^{18-20}$ COX-2 inhibitors were confirmed to induce apoptosis, enhance the cytotoxicity of anticancer drugs, exert antiangiogenesis effects in lung cancer models, restore antitumor immunity, and reduce tumor invasion. ${ }^{18-23}$ Some clinical trials have made a special assessment of the role of the highly selective COX-2 inhibitor, celecoxib, in advanced/metastatic NSCLC. Csiki et $\mathrm{al}^{24}$ evaluated the efficacy of celecoxib combined with docetaxel in the second-line treatment of metastatic NSCLC and showed that prostaglandin E2 (PGEM) levels produced by COX-2 were inhibited and that the survival time of patients was prolonged. Fidler et $\mathrm{al}^{25}$ suggested that celecoxib combined with erlotinib for the treatment of previously treated stage IIIB/IV NSCLC patients significantly prolonged progression-free survival (PFS) in those with high expression of COX-2 (5.6 vs 2.0 months, $P=0.048)$. The Cancer and Leukemia Group B 30,203 study reported that advanced NSCLC patients with overexpression of COX-2 who received celecoxib had a better prognosis than those who did not receive celecoxib. Moreover, tumor response was better in patients with intermediate and high levels of COX-2 based on median OS (11.2 vs 3.8 months). ${ }^{17}$ These studies suggested that celecoxib may have clinical therapeutic effects in the treatment of patients with advanced NSCLC.

Based on these observations, many clinical trials have been conducted to investigate the efficacy and safety of celecoxib in advanced NSCLC. However, the rates of tumor response, survival, and toxicity among these trials are statistically incompatible. Some clinical Phase II trials have shown that the efficacy of a selective COX-2 inhibitor, celecoxib, combined with chemotherapy in NSCLC was better than that of chemotherapy alone. ${ }^{26,27}$ However, other trials have shown that celecoxib combinations did not improve the survival rate of patients with advanced NSCLC. ${ }^{28}$ This variability may be due to the limited number of patients in each trial or combinations with celecoxib in different lines of treatment. A meta-analysis assessed the efficacy of COX-2 inhibitors (celecoxib, rofecoxib, or apricoxib) in combination with chemotherapy in advanced NSCLC patients. ${ }^{29}$ The results of this study showed that COX-2 inhibitors combined with first-line chemotherapy significantly improved the overall response rate (ORR) (risk ratio $[\mathrm{RR}]=1.27,95 \% \mathrm{CI}=1.07-1.50$ ), but subgroup analysis including only 4 studies showed that celecoxib plus chemotherapy yielded no significant difference in patients with advanced NSCLC $(\mathrm{RR}=1.18,95 \% \mathrm{CI}$ $\left.=0.98-1.42, I^{2}=0.0 \%, P=0.562\right)$. Additionally, this study reported that COX-2 inhibitors with chemotherapy led to higher incidences of cardiovascular events $(\mathrm{RR}=2.39,95 \%$ $\mathrm{CI}=1.06-5.42$ ). Currently, there is no relevant report on evaluating the efficacy of celecoxib combined with systemic therapy (including chemotherapy, radiotherapy, and TKIs) exclusively for advanced NSCLC.

To improve the effects of celecoxib, we conducted this systematic review and meta-analysis to assess the efficacy and safety of celecoxib combined with systemic therapies in the treatment of advanced NSCLC and to explore the potential mechanisms. The primary endpoints were ORR, one-year survival, OS, and PFS. In addition, subgroup analysis was performed according to different lines of treatment in terms of ORR, 1-year survival, and partial response (PR).

\section{Materials and methods}

\section{Search strategy}

This systematic review was conducted according to the Preferred Reporting Items for Systematic reviews and Meta-Analyses (PRISMA) statement. ${ }^{30}$ Three databases, including PubMed, EMBASE, and the Cochrane Library, were systematically searched to identify studies related to celecoxib combined with systemic therapy in NSCLC patients. The search was performed from the date of inception through March 1, 2018, in each database without restrictions 
of time and language. The following search terms were used: "Celecoxib or COX-2 inhibitor or COX-2 inhibition," "nonsmall cell lung cancer or non-small cell lung carcinoma or NSCLC," and "clinical trial." Additionally, we manually searched the references of all retrieved articles to identify additional studies that met the inclusion criteria.

\section{Selection criteria}

Studies that met all the following criteria were included: 1) patients histologically diagnosed with NSCLC; 2) randomized clinical trials (RCTs) designed to evaluate the efficacy and safety profile of adding celecoxib to systemic therapy in only patients with advanced NSCLC; 3) the eligible patients enrolled were adult patients with Eastern Cooperative Oncology Group (ECOG) performance status 0-2 and normal hematologic, renal, and hepatic functions; 4) number of advanced NSCLC patients enrolled $<20 ; 5$ ) full paper in English was published; 6) the retrieved study had sufficient data on tumor response, survival, and toxicities; and 7) the most recent and complete report of the trial was included when the same investigator reported data resulting from the same patients. Single-arm trials, case reports, animal or in vitro experiments, and other irrelevant studies were excluded. Trials with incomplete data were also excluded.

\section{Data extraction and quality assessment}

Two reviewers (LLY and WZ) searched potentially relevant papers and reviewed all the studies according to the selection criteria independently. Data extraction was performed by two reviewers independently after developing the data extraction template in advance. Any discrepancies between the 2 reviewers were resolved through discussion and consultation with the third reviewer (PL). The following items were collected from all the retrieved studies: first investigator's name, study design, country, study period, line of treatment, age (years), ECOG performance status, sample size, treatment pattern, treatment program, and dose and length of celecoxib treatment. When the necessary data were provided in a graph in the paper, Engauge Digitizer version 4.1 (http://digitizer. sourceforge.net/) was employed to extract the corresponding data. The risk of bias of the included RCTs was evaluated by two reviewers applying the Cochrane Collaboration Tool (Cochrane Library, Oxford, UK). ${ }^{31}$

\section{Statistical analysis}

The intent-to-treat analysis was employed to calculate tumor response, one-year survival, OS, and PFS. The differences between the experimental and control groups were estimated by pooling the RR, and the corresponding 95\% CI was presented for each effect size. The heterogeneity among studies was determined by the $\chi^{2}$ test and $I^{2}$ statistic. An $I^{2}$ statistic $<50 \%$ indicated no statistically significant heterogeneity between studies. ${ }^{32}$ In the absence of heterogeneity, the fixed-effects model was used to calculate the pooled RR; otherwise, the random-effects model was used. All $P$-values were 2 -sided, and a statistical $P$-value of $<0.05$ was considered significant. Publication bias was visually assessed in a funnel plot. Additionally, Begg's test and Egger's test were employed to quantitatively estimate the publication bias of the included studies. Aggregated OS and PFS survival curves were plotted using the Kaplan-Meier method with SPSS 23 (IBM Corporation, Armonk, NY, USA). The log-rank test was applied to examine the differences in OS and PFS between study groups. The meta-analysis was conducted using Review Manager 5.3 developed by the Cochrane Collaboration (Cochrane Library).

\section{Results}

\section{Characteristics of the studies and quality assessment}

The detailed process of the PRISMA flowchart is shown in Figure 1 . A total of 128 potentially relevant records were reviewed based on the initial search strategy. Eventually, a total of $7 \mathrm{RCT}$ s that met the inclusion criteria were identified. ${ }^{17,28,33-37}$ The baseline characteristics of the 7 RCTs included are presented in Table 1. The eligible studies involved 1,559 patients with advanced NSCLC, of whom 780 received combination therapy with celecoxib and 779 received systemic therapy alone. The studies included were published from 2006 to 2017, and the sample size in each study ranged from 20 to 281. Four studies were Phase II RCTs, while three studies were Phase III RCTs. The ECOG performance status of patients ranged from 0 to 2 . Almost all included patients had advanced or metastatic NSCLC, but 1 patient each with stage IIB was included in both the celecoxib group and placebo group. ${ }^{33}$ Two trials investigated second-line treatments, and 5 trials investigated first-line treatments. ${ }^{17,33-35,37}$ Five studies involved celecoxib combined with chemotherapy, ${ }^{17,28,34,35,37}$ while celecoxib was combined with radiotherapy in one trial, ${ }^{33}$ and the other was related to TKIs. ${ }^{36}$ Except for a dose of $600 \mathrm{mg}$ used in 1 trial, ${ }^{36}$ the dose of celecoxib used was $400 \mathrm{mg}$ in the other 6 trials. ${ }^{17,28,33-35,37}$ The risk of bias assessment for each study is summarized in Figure 2.

\section{Tumor response}

Six RCTs reported ORR data. The pooled ORR of celecoxib added to systemic therapy was $31.3 \%(196 / 626)$ and that 


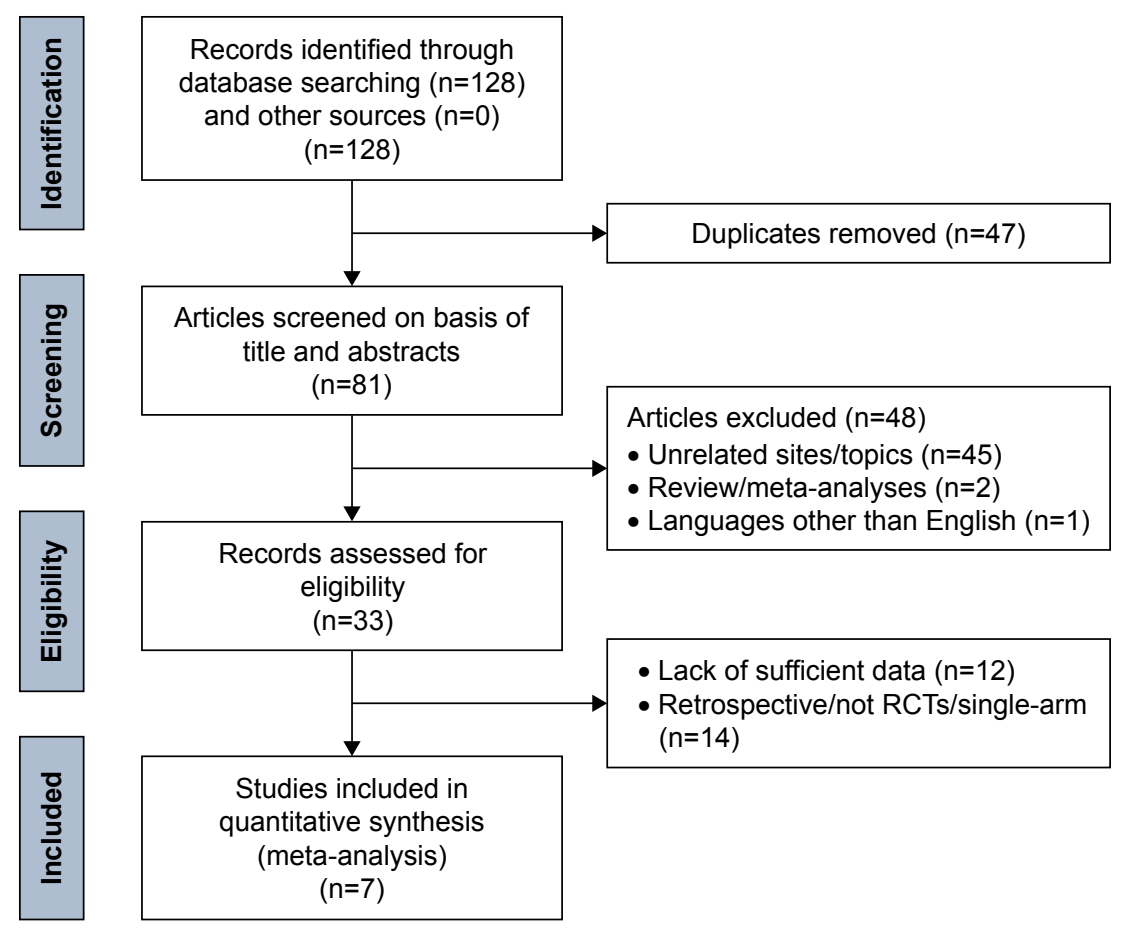

Figure I Flowchart of study selection according to PRISMA guidelines.

Abbreviations: PRISMA, Preferred Reporting Items for Systematic reviews and Meta-Analyses; RCTs, randomized clinical trials.

of therapy without celecoxib was $27.5 \%(171 / 621)$, with no significant difference $(\mathrm{RR}=1.14,95 \% \mathrm{CI}=0.96-1.35$, $P=0.13)\left(I^{2}=0 \%, P=0.50\right)$. To better evaluate the efficacy of celecoxib in advanced NSCLC, we performed further subgroup analysis of ORR according to the line of treatment. The ORR was $36.0 \%(182 / 505)$ for patients who received celecoxib and $29.9 \%(150 / 502)$ for patients treated with the placebo. Thus, the ORR was significantly increased for celecoxib as a first-line treatment $(\mathrm{RR}=1.21,95 \% \mathrm{CI}=1.01-1.44$, $P=0.04)\left(I^{2}=0 \%, P=0.90\right)$. However, there was no significant difference in ORR between the celecoxib and placebo groups in the second-line treatment setting $(\mathrm{RR}=0.65,95 \%$ $\mathrm{CI}=0.36-1.19, P=0.16$ ) (Figure 3).

Four RCTs including 824 patients reported PR data. Similarly, the combined PR was $29.7 \%$ (123/414) vs $24.1 \%$ (99/410) in the celecoxib vs placebo groups $(\mathrm{RR}=1.23,95 \%$ $\mathrm{CI}=0.99-1.54, P=0.06)\left(I^{2}=0 \%, P=0.55\right)($ Table 2$)$. Subgroup analysis showed that the PR was significantly increased in the celecoxib group during first-line treatment $(\mathrm{RR}=1.26,95 \%$ $\mathrm{CI}=1.01-1.58, P=0.04)\left(I^{2}=0 \%, P=0.63\right)$ (Figure $\left.\mathrm{S} 1\right)$.

Clinical benefit (CB) and stable disease (SD) were reported in 6 studies including 1,247 patients. The pooled $\mathrm{CB}$ values in patients receiving celecoxib and placebo were $71.9 \%(450 / 626)$ and $69.9 \%(434 / 621)$, respectively, with no significant difference ( $\mathrm{RR}=1.03,95 \% \mathrm{CI}=0.96-1.10$, $P=0.38)\left(I^{2}=0 \%, P=0.79\right)$ (Table 2). In addition, there was no significant increase in the celecoxib group in terms of SD (RR $=0.96,95 \% \mathrm{CI}=0.84-1.09, P=0.53)\left(I^{2}=0 \%\right.$, $P=0.43$ ) (Table 2).

\section{Survival}

The 1-year survival rate was $39.2 \%$ (306/780) for patients treated with celecoxib and 39.5\% (308/779) for patients treated with placebo. Accordingly, the effect was ambiguous for both celecoxib and placebo, with an RR of 0.99 (95\% $\mathrm{CI}=0.88-1.12, P=0.91)\left(I^{2}=0 \%, P=0.57\right)$. Based on the lack of significant improvement in the one-year survival in nonselected patients, further analysis was carried out to explore the subgroups that might benefit from celecoxib. According to the subgroup analysis mentioned above, additional celecoxib did not significantly differ from systemic therapy in terms of first-line treatment $(\mathrm{RR}=1.04,95 \% \mathrm{CI}=0.91-1.19, P=0.58)$ $\left(I^{2}=0 \%, P=0.79\right)$. It also did not yield a significant difference in second-line therapy ( $\mathrm{RR}=0.79,95 \% \mathrm{CI}=0.59-1.05$, $P=0.11)\left(I^{2}=0 \%, P=0.33\right)$ (Figure 3$)$. On the basis of the reported 6-month OS (OS-6), the combined analysis showed that the difference in OS-6 between the celecoxib and placebo groups was not statistically significant $(\mathrm{RR}=0.98$, 95\% CI $=0.92-1.06, P=0.67)\left(I^{2}=0 \%, P=0.55\right)$ (Table 2). In addition, pooled analysis demonstrated that the 6-month PFS (PFS-6) of celecoxib and placebo was similar, at 37.2\% $(178 / 478)$ and $38.0 \%(182 / 479)$, respectively $(R R=0.98$, 


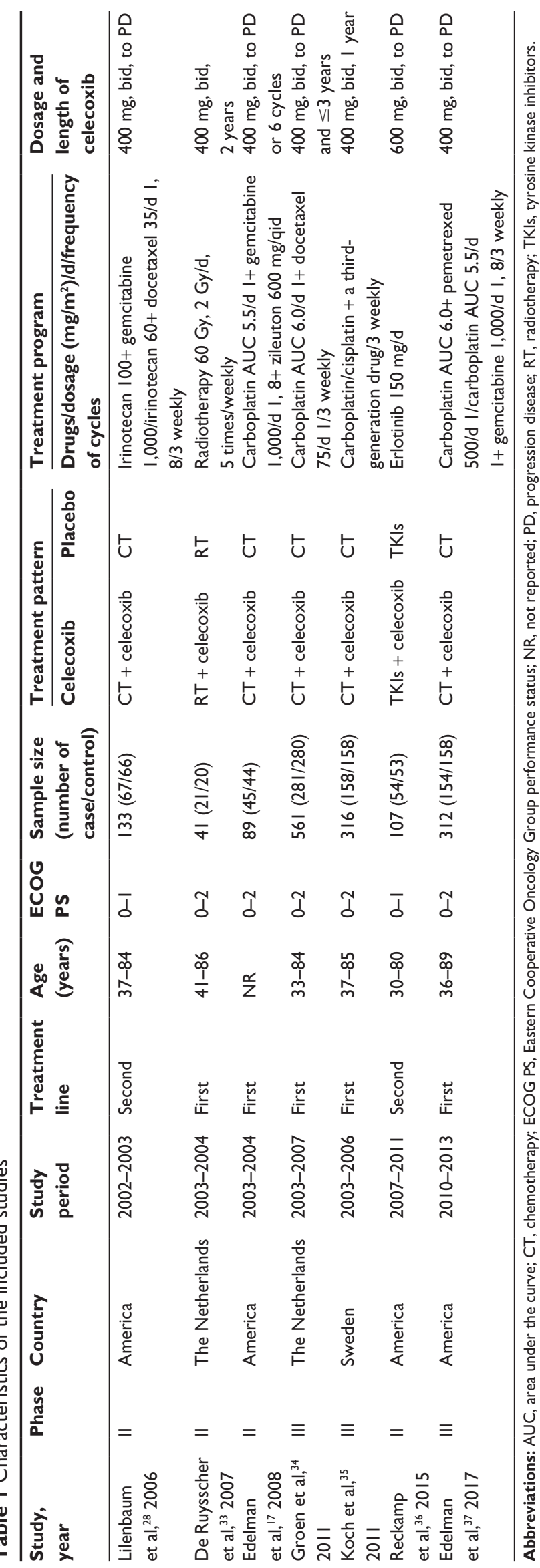

95\% CI $=0.84-1.15, P=0.82)\left(I^{2}=36 \%, P=0.18\right)($ Table 2$)$ A similar result was found for the 12-month PFS (PFS-12) in both the celecoxib and placebo groups ( $R R=0.99,95 \%$ CI $=0.69-1.41, P=0.94)\left(I^{2}=24 \%, P=0.27\right)($ Table 2$)$.

After the available data from the included studies were pooled, the five-year OS for the celecoxib and placebo groups was similar (median, 12.9 vs 12.5 months, $P=0.553$, Figure 4A). Additionally, the 5-year PFS was not significantly improved in the celecoxib arm (median, 7.4 vs 7.2 months, $P=0.641$, Figure 4B).

\section{Toxicities}

Grade III or higher toxicities of celecoxib combined with systemic therapy in patients with advanced NSCLC were evaluated. The common toxicities caused by celecoxib were analyzed, including hematologic toxicities such as anemia, leukopenia, neutropenia, and thrombocytopenia, as well as nonhematologic toxicities such as nausea or vomiting, diarrhea, fatigue, thrombosis or embolism, cardiac ischemia, dyspnea, and rash. The pooled relative risk of leukopenia and thrombocytopenia was $1.25(95 \% \mathrm{CI}=1.03-1.50, P=0.02)$ and $1.39(95 \% \mathrm{CI}=1.11-1.75, P=0.005)$, respectively, which indicated that celecoxib increased the hematologic toxicity associated with systemic therapy. However, additional celecoxib did not increase the risks of thrombosis or embolism $(\mathrm{RR}=1.26,95 \% \mathrm{CI}=0.66-2.39, P=0.48)$ and cardiac ischemia $(\mathrm{RR}=1.16,95 \% \mathrm{CI}=0.39-3.44, P=0.78)$. In addition, the risk of rash in the celecoxib group was significantly increased ( $R R=7.75,95 \% \mathrm{CI}=1.43-42.10$, $P=0.02)$. No significant increase in the risk of other toxicities was observed (Table 3).

\section{Publication bias}

Funnel charts were used to estimate the publication bias of ORR and 1-year survival, which showed no obvious asymmetry (Figure S2). Moreover, both Begg's test and Egger's test indicated no significant publication bias $(P>0.05)$. This finding suggested that no publication bias affected the results of this meta-analysis.

\section{Discussion}

COX-2 can be upregulated by growth factors, cytokines, carcinogens, and other stimulants and is overexpressed in a variety of malignant tumors, including NSCLC. ${ }^{16} \mathrm{COX}-2$ affects tumor progression by multiple approaches, including angiogenesis, resistance to apoptosis, tumor invasion, metastasis, and host immunity. ${ }^{38}$ In addition, COX-2 was associated with the overexpression of phosphorylated 
A

Random sequence generation (selection bias)

Allocation concealment (selection bias)

Blinding of participants and personnel (performance bias)

Blinding of outcome assessment (detection bias)

Incomplete outcome data (attrition bias)

Selective reporting (reporting bias)

Other bias
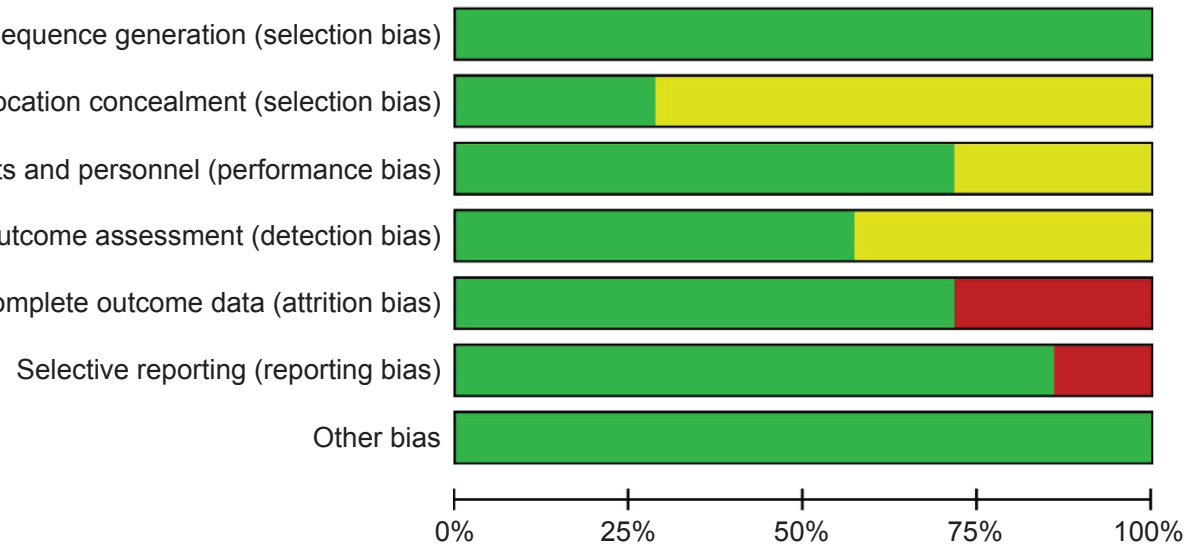

Low risk of bias $\square$ Unclear risk of bias $\square$ High risk of bias

B

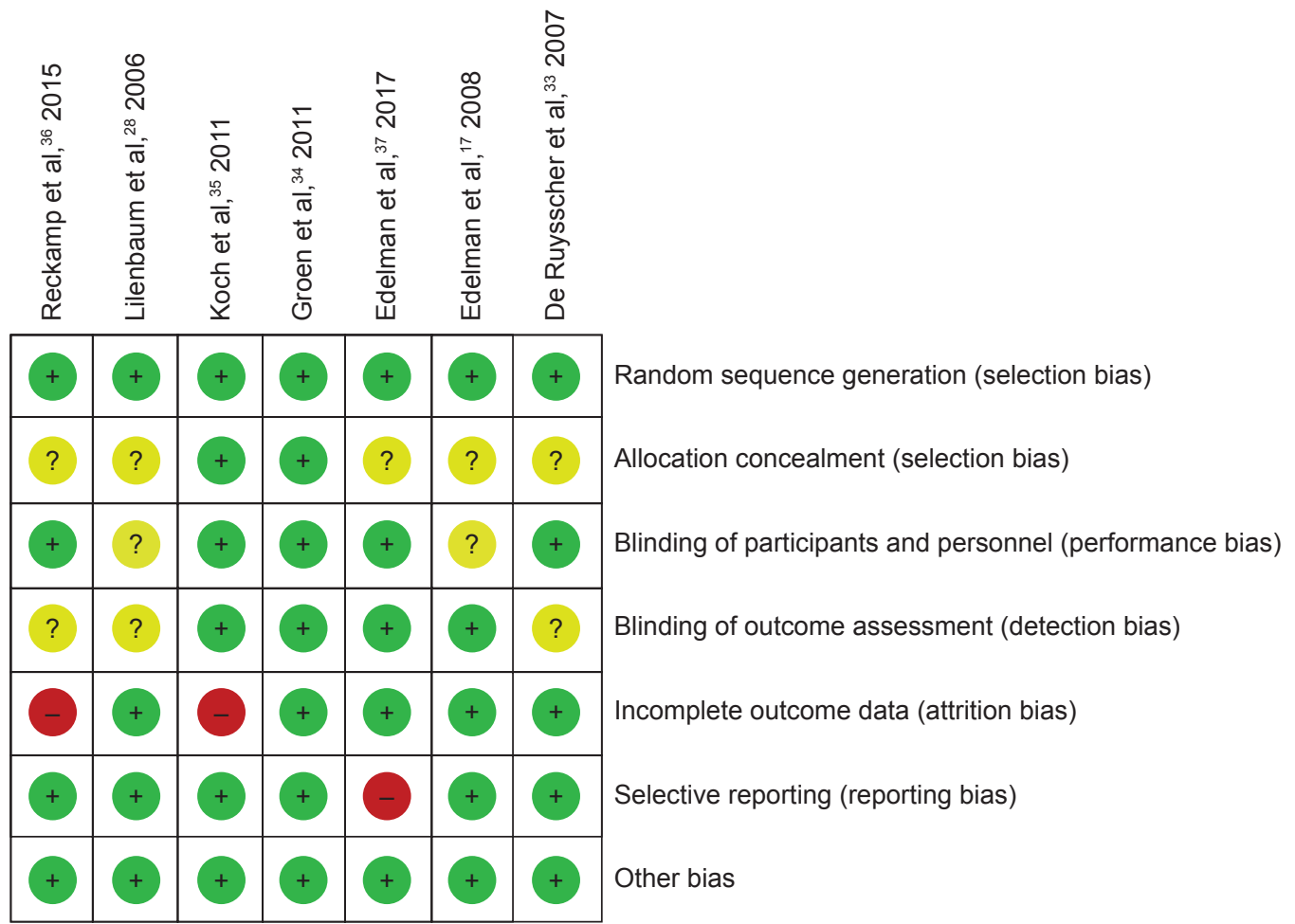

Figure 2 Risk of bias graph (A) and risk of bias summary (B) of enrolled studies.

glycoproteins, and the inhibition of COX may potentially reverse drug resistance. ${ }^{39}$ Moreover, new evidence suggests that the mechanism of COX-2 is related to immune evasion (an important focus for the validation of immune checkpoint inhibitors in advanced NSCLC) ${ }^{40}$ The highly selective COX-2 inhibitor celecoxib induces the apoptosis of NSCLC cells and enhances the antitumor activity of standard chemotherapeutic drugs. ${ }^{41}$ In addition, celecoxib has been reported to reduce the adverse reactions caused by radiotherapy, such as radioactive pneumonia. ${ }^{33}$ However, there are differences in the outcomes among clinical trials of celecoxib in advanced NSCLC. ${ }^{17,28}$ Thus, it is necessary to assess the CBs of celecoxib for advanced NSCLC patients.

Seven eligible RCTs with 1,559 patients were identified to obtain summary statistics in the present meta-analysis. The pooled results showed that celecoxib combined with systemic treatment failed to significantly increase the tumor response rate, including ORR, $\mathrm{CB}, \mathrm{PR}$, and $\mathrm{SD}$ in patients with advanced NSCLC. This result may be due to the several different treatment combinations in the included studies. According to the exploratory analysis of differ- 


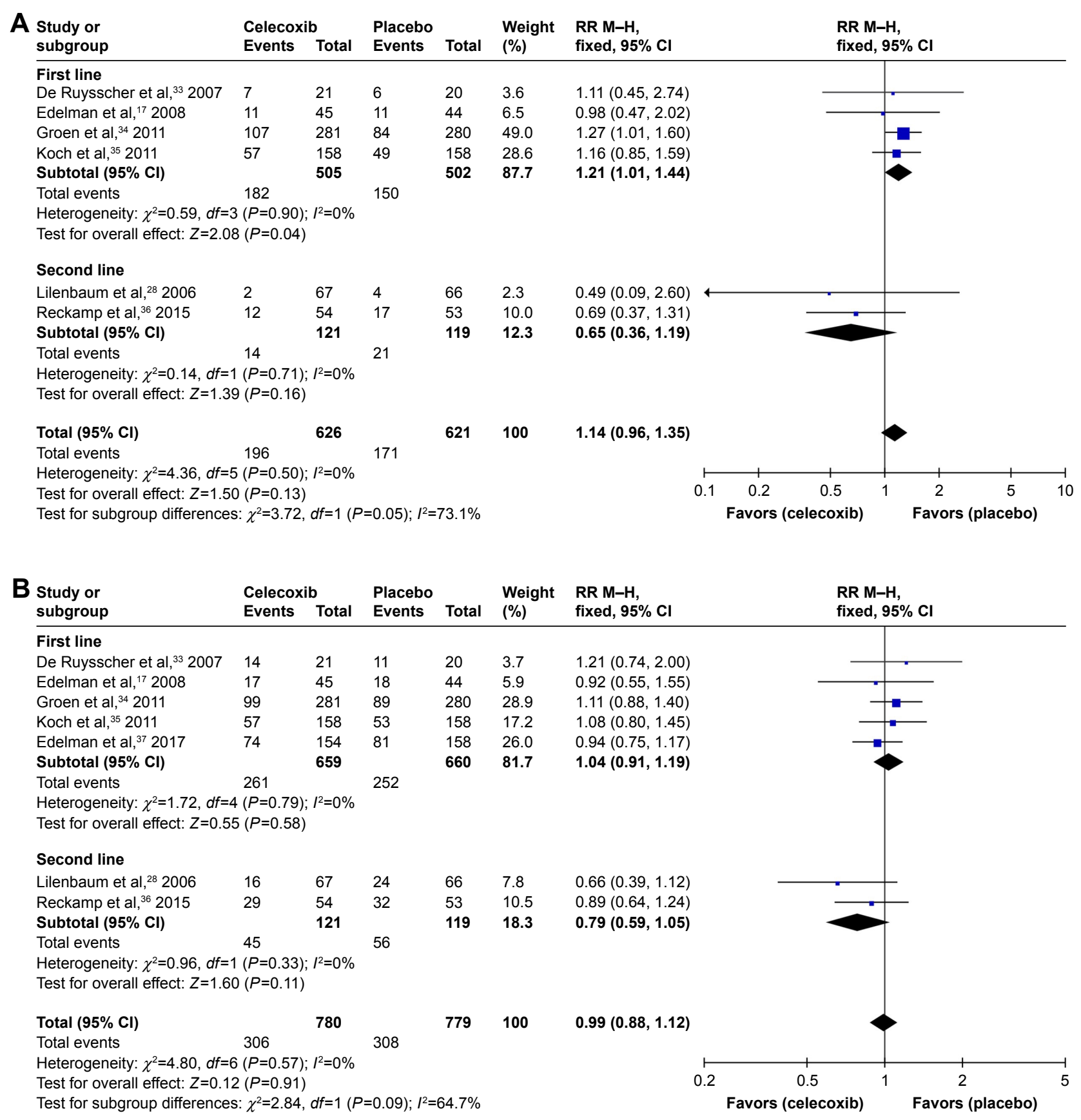

Figure 3 Forest plots for subgroup analysis of the ORR and I-year survival (OS-12) according to the line of treatment.

Note: (A) ORR and (B) OS-12.

Abbreviations: M-H, Mantel-Haenszel; ORR, overall response rate; OS, overall survival; RR, risk ratio.

Table 2 Meta-analysis of secondary endpoints in advanced NSCLC

\begin{tabular}{|c|c|c|c|c|c|c|}
\hline \multirow[t]{2}{*}{ Outcomes } & \multirow{2}{*}{$\begin{array}{l}\text { Number } \\
\text { of RCTs }\end{array}$} & \multicolumn{2}{|l|}{ Patients } & \multirow[t]{2}{*}{$\operatorname{RR}(95 \% \mathrm{Cl})$} & \multirow[t]{2}{*}{$P$-value } & \multirow{2}{*}{$\begin{array}{l}\text { Heterogeneity } \\
\left(I^{2}, P \text {-value }\right)\end{array}$} \\
\hline & & Celecoxib & Placebo & & & \\
\hline CB & 6 & $450 / 626$ & $434 / 621$ & $1.03(0.96-1.10)$ & 0.38 & $0 \%, 0.79$ \\
\hline PR & 4 & $|23 / 4| 4$ & $99 / 410$ & $1.23(0.99-1.54)$ & 0.06 & $0 \%, 0.55$ \\
\hline SD & 6 & $254 / 626$ & $263 / 621$ & $0.96(0.84-1.09)$ & 0.53 & $0 \%, 0.43$ \\
\hline OS-6 & 6 & $496 / 759$ & $504 / 759$ & $0.98(0.92-1.06)$ & 0.67 & $0 \%, 0.55$ \\
\hline PFS-6 & 5 & I 78/478 & $182 / 479$ & $0.98(0.84-1.15)$ & 0.82 & $36 \%, 0.18$ \\
\hline PFS-12 & 4 & $53 / 4 I I$ & $54 / 413$ & $0.99(0.69-1.4 I)$ & 0.94 & $24 \%, 0.27$ \\
\hline
\end{tabular}

Abbreviations: CB, clinical benefit; NSCLC, non-small-cell lung cancer; OS-6, 6-month overall survival; PFS-6, 6-month progression-free survival; PFS-12, 12-month progression-free survival; PR, partial response; RCTs, randomized controlled trials; RR, risk ratio; SD, stable disease. 

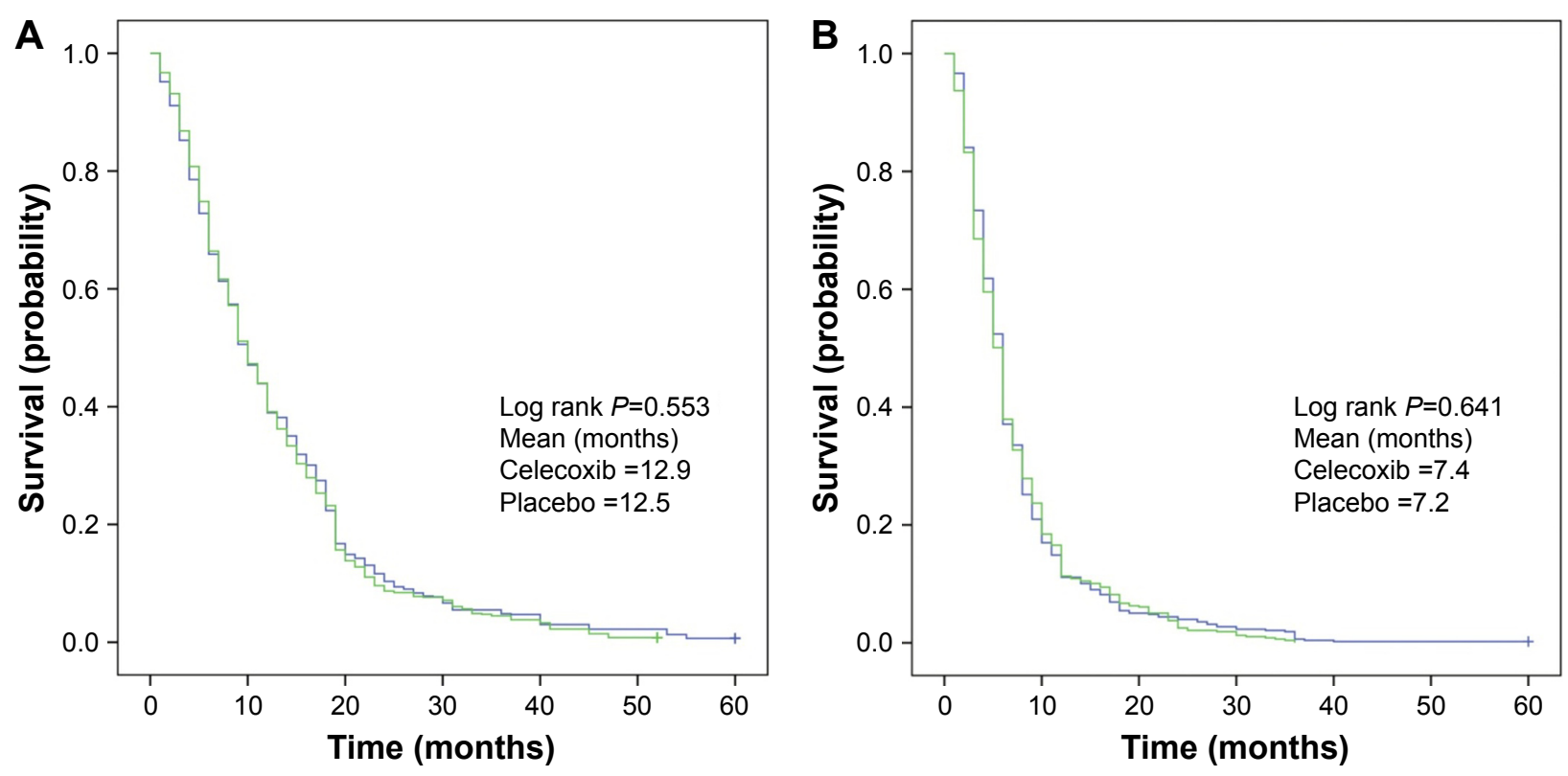

$\neg$ Celecoxib $\_$Placebo

Figure 4 Kaplan-Meier estimates of OS and PFS of patients treated with celecoxib or placebo.

Note: (A) OS and (B) PFS.

Abbreviations: OS, overall survival; PFS, progression-free survival.

ent joint modes, celecoxib combined with chemotherapy, radiotherapy, or TKI treatment had no significant difference compared to the placebo arm (data not shown). Interestingly, based on subgroup analysis of the line of treatment, celecoxib significantly improved ORR $(P=0.04)$ and PR $(P=0.04)$ in first-line treatment. However, there was no significant increase in ORR $(P=0.16)$ for secondline treatment involving celecoxib. Indeed, several studies have shown that COX-2 enhances the antitumor activity of traditional chemotherapeutic drugs, especially taxanes, in vivo and in vitro. ${ }^{26,42}$ Moreover, studies have indicated that the additional application of COX-2 inhibitors increases the toxicity of various chemotherapeutic drugs. Compared with etoposide and cisplatin, the combination of COX-2 and irinotecan and docetaxel significantly induced the apoptosis of NSCLC cells. ${ }^{18}$ In addition, Mutter et al ${ }^{43}$ suggested an apparent relationship between PGEM levels and tumor response $(P=0.005)$ but not survival $(P=0.114)$. Therefore,

Table 3 Meta-analysis of toxicities in advanced NSCLC patients randomly assigned to celecoxib or placebo

\begin{tabular}{|c|c|c|c|c|c|c|}
\hline \multirow[t]{2}{*}{ Toxicity } & $\mathbf{N}$ & Celecoxib & Placebo & \multirow[t]{2}{*}{$\operatorname{RR}(95 \% \mathrm{Cl})$} & \multirow[t]{2}{*}{$P$-value } & \multirow{2}{*}{$\begin{array}{l}\text { Heterogeneity } \\
\left(I^{2}, P \text {-value }\right)\end{array}$} \\
\hline & \multicolumn{3}{|c|}{ No $\geq$ Grade III } & & & \\
\hline \multicolumn{7}{|l|}{ Hematologic } \\
\hline Anemia & 4 & $66 / 424$ & $54 / 426$ & $1.24(0.90-1.69)$ & 0.19 & $45 \%, 0.14$ \\
\hline Leucopenia & 3 & $173 / 593$ & $139 / 596$ & $1.25(1.03-1.50)$ & 0.02 & $24 \%, 0.27$ \\
\hline Neutropenia & 4 & $202 / 547$ & I79/548 & $1.13(0.96-1.32)$ & 0.14 & $0 \%, 0.85$ \\
\hline Thrombocytopenia & 5 & $133 / 705$ & $96 / 706$ & $1.39(1.11-1.75)$ & 0.005 & $0 \%, 0.60$ \\
\hline Febrile neutropenia & 4 & $35 / 547$ & $34 / 548$ & $1.03(0.66-1.61)$ & 0.9 & $0 \%, 0.58$ \\
\hline \multicolumn{7}{|l|}{ Nonhematologic } \\
\hline Nausea/vomiting & 3 & $20 / 480$ & $18 / 482$ & $1.22(0.32-4.66)$ & 0.78 & $67 \%, 0.05$ \\
\hline Diarrhoea & 2 & $12 / 435$ & $1 \mathrm{l} / 438$ & $1.09(0.50-2.39)$ & 0.83 & $50 \%, 0.16$ \\
\hline Fatigue/Asthenia & 2 & $26 / 435$ & $27 / 438$ & $0.97(0.58-1.64)$ & 0.91 & $0 \%, 0.45$ \\
\hline $\begin{array}{l}\text { Thrombosis or } \\
\text { embolism }\end{array}$ & 3 & $19 / 357$ & $15 / 360$ & $1.26(0.66-2.39)$ & 0.48 & $0 \%, 0.66$ \\
\hline Cardiac ischaemia & 3 & $6 / 480$ & $5 / 482$ & I. $16(0.39-3.44)$ & 0.78 & $0 \%, 0.41$ \\
\hline Rash & 2 & $11 / 435$ & $\mathrm{I} / 438$ & $7.75(1.43-42.10)$ & 0.02 & $0 \%, 0.45$ \\
\hline Dyspnea & 2 & $5 / 435$ & $4 / 438$ & $1.26(0.34-4.67)$ & 0.73 & $0 \%, 0.36$ \\
\hline
\end{tabular}

Abbreviations: $\mathrm{Cl}$, confidence interval; $\mathrm{N}$, number of included studies; $\mathrm{RR}$, risk ratio. 
celecoxib may improve local control by increasing the efficacy of chemotherapy and may have little or no impact on survival.

This study found that celecoxib had no significant effects on OS and PFS in patients with advanced NSCLC, including 1-year survival, OS-6, PFS-6, and PFS-12. This finding may be associated with the use of celecoxib in unselected NSCLC patients. Biomarkers, such as COX-2 and PGEM, may have predictive value for the treatment of celecoxib, contributing to the identification of patients who will benefit from celecoxib. The Phase III RCT performed by Groen et $\mathrm{al}^{34}$ showed that celecoxib combined with carboplatin and docetaxel did not significantly improve OS in unselected NSCLC patients. The CALGB 30203 study suggested that patients with overexpression of COX-2 had better effects with celecoxib than those who did not receive celecoxib, and multivariate analysis confirmed the independent predictive value of COX-2 and the response to celecoxib ( $\mathrm{HR}=0.17,95 \% \mathrm{CI}=0.06-0.49, P=0.001) .{ }^{17}$ However, the CALGB 30801 (Alliance) study did not confirm that the combination with celecoxib in advanced NSCLC patients based on COX-2 expression could improve clinical outcomes. ${ }^{37}$ Another option to estimate the effect of COX-2 is to measure the urine PGEM, which can be evaluated in real time. Csiki et $\mathrm{al}^{24}$ indicated that celecoxib combined with chemotherapy did not improve the OS of patients with advanced NSCLC, but OS was significantly prolonged in patients with low levels of PGEM. Another study suggested that the combination of celecoxib and erlotinib improves PFS in patients with higher baseline levels of PGEM. ${ }^{36}$ The partial benefit to patients is probably because celecoxib inhibits COX-2 expression induced by chemotherapy and reduces the level of intratumoral COX-2 and PGEM. Altorki et a $1^{44}$ evaluated the expression of COX-2 after neoadjuvant chemotherapy in locally advanced NSCLC patients and showed that the level of intratumoral COX-2 was 3 times as high as that in patients who were not subjected to chemotherapy. This effect was inhibited when celecoxib was combined with chemotherapy. Furthermore, if the serum levels of VEGF were $<200 \mathrm{pg} / \mathrm{mL}$ before treatment, celecoxib could improve the survival of patients with NSCLC compared to the controls..$^{45}$ Consequently, the use of the optimum biomarkers may provide additional improvements for combination treatments with celecoxib for NSCLC patients.

The cardiovascular toxicity of celecoxib has always been a topic of debate in this field. ${ }^{46}$ Cardiovascular toxicities associated with COX-2 inhibitors have restricted its application and research in cancer. Therefore, 2 RCTs failed to accomplish volunteer recruitment according to the original plan. ${ }^{28,33}$ The current meta-analysis found that celecoxib did not significantly increase the risk of thrombus or embolism $(P=0.48)$ or the risk of myocardial ischemia $(P=0.78)$ at grade III or higher. Celecoxib at a high dose (800 mg bid) may be related to a high risk of cardiovascular events, while $400 \mathrm{mg}$ celecoxib bid had little risk of cardiovascular events. ${ }^{47}$ Except one study that used a dose of $600 \mathrm{mg}$ bid, celecoxib was used at a dose of $400 \mathrm{mg}$ bid in 6 studies. Nevertheless, the hematological toxicity of leukopenia and thrombocytopenia was significantly higher in the celecoxib group than in the placebo group (Table 2). The expression of COX-2 is increased in tumor bone marrow cells, and COX-2 plays an important role in the recovery of bone marrow after chemotherapy, which may be related to leukopenia and thrombocytopenia. ${ }^{48}$ Preclinical data showed that mice lacking the $\mathrm{COX}-2$ gene have a slower recovery of bone marrow after exposure to 5 -fluorouracil than wild-type mice. When hemolysis was induced in COX-2-deficient mice, erythrocyte formation was unimpeded compared to wild-type mice. These data suggested that COX-2 is essential for repairing bone marrow damage but is not necessary for normal bone marrow hematology. ${ }^{49}$

Additionally, this study still has some potential limitations. First, although there was no significant publication bias evident in the funnel plot, the small number of trials, especially in the subgroup analysis, restricted the statistical efficacy. Second, only published RCTs were included, with three Phase III trials and four Phase II trials. Third, not all RCTs provided sufficient data on the ORR and survival indices, which affected the summarized results of the present meta-analysis. Furthermore, the numbers of eligible studies and enrolled patients were not significant. These factors suggest that our study may have clinical and methodological heterogeneity. Therefore, we could not draw exact conclusions from the data, and research endeavors should be continued in future trials.

\section{Conclusion}

Celecoxib had moderate antitumor activity for advanced NSCLC without increasing the risk of cardiovascular events. In first-line treatment, celecoxib combined with systemic therapy may improve the tumor response rate in patients with advanced NSCLC. In addition, celecoxib may also increase hematological toxicities. Whether or not it is worth trying adding COX-2 to the combination of chemotherapy and immunotherapy would further improve the outcome is debatable. 


\section{Disclosure}

The authors report no conflicts of interest in this work.

\section{References}

1. Torre LA, Siegel RL, Jemal A. Lung cancer statistics. Adv Exp Med Biol. 2016;893:1-19.

2. Siegel RL, Miller KD, Jemal A. Cancer statistics, 2018. CA Cancer J Clin. 2018;68(1):7-30.

3. Arnold M, Pandeya N, Byrnes G, et al. Global burden of cancer attributable to high body-mass index in 2012: a population-based study. Lancet Oncol. 2015;16(1):36-46.

4. Mok TS, Wu YL, Thongprasert S, et al. Gefitinib or carboplatinpaclitaxel in pulmonary adenocarcinoma. NEngl J Med. 2009;361(10): 947-957.

5. Garassino MC, Martelli O, Broggini M, et al. Erlotinib versus docetaxel as second-line treatment of patients with advanced non-small-cell lung cancer and wild-type EGFR tumours (TAILOR): a randomised controlled trial. Lancet Oncol. 2013;14(10):981-988.

6. Schiller JH, Harrington D, Belani CP, et al. Comparison of four chemotherapy regimens for advanced non-small-cell lung cancer. $N$ Engl J Med. 2002;346(2):92-98.

7. Azzoli CG, Baker S Jr, Temin S, et al. American Society of Clinical Oncology Clinical Practice Guideline update on chemotherapy for stage IV non-small-cell lung cancer. J Clin Oncol. 2009;27(36): 6251-6266.

8. Patel JD, Socinski MA, Garon EB, et al. PointBreak: a randomized phase III study of pemetrexed plus carboplatin and bevacizumab followed by maintenance pemetrexed and bevacizumab versus paclitaxel plus carboplatin and bevacizumab followed by maintenance bevacizumab in patients with stage IIIB or IV nonsquamous non-small-cell lung cancer. J Clin Oncol. 2013;31(34):4349-4357.

9. Mudad R, Patel MB, Margunato-Debay S, Garofalo D, Lal LS. Comparative effectiveness and safety of nab-paclitaxel plus carboplatin vs gemcitabine plus carboplatin in first-line treatment of advanced squamous cell non-small cell lung cancer in a US community oncology setting. Lung Cancer. 2017;8:179-190.

10. Scagliotti GV, De Marinis F, Rinaldi M, et al. Phase III randomized trial comparing three platinum-based doublets in advanced non-small-cell lung cancer. J Clin Oncol. 2002;20(21):4285-4291.

11. Coussens LM, Werb Z. Inflammation and cancer. Nature. 2002; 420(6917):860-867.

12. Mantovani A, Allavena P, Sica A, Balkwill F. Cancer-related inflammation. Nature. 2008;454(7203):436-444.

13. Khuri FR, Wu H, Lee JJ, et al. Cyclooxygenase-2 overexpression is a marker of poor prognosis in stage I non-small cell lung cancer. Clin Cancer Res. 2001;7(4):861-867.

14. Wolff H, Saukkonen K, Anttila S, Karjalainen A, Vainio H, Ristimaki A. Expression of cyclooxygenase-2 in human lung carcinoma. Cancer Res. 1998;58(22):4997-5001.

15. Ochiai M, Oguri T, Isobe T, Ishioka S, Yamakido M. Cyclooxygenase-2 (COX-2) mRNA expression levels in normal lung tissues and non-small cell lung cancers. Jpn J Cancer Res. 1999;90(12):1338-1343.

16. Hida T, Yatabe Y, Achiwa H, et al. Increased expression of cyclooxygenase 2 occurs frequently in human lung cancers, specifically in adenocarcinomas. Cancer Res. 1998;58(17):3761-3764.

17. Edelman MJ, Watson D, Wang X, et al. Eicosanoid modulation in advanced lung cancer: cyclooxygenase-2 expression is a positive predictive factor for celecoxib + chemotherapy - Cancer and Leukemia Group B Trial 30203. J Clin Oncol. 2008;26(6):848-855.

18. Hida T, Kozaki K, Muramatsu H, et al. Cyclooxygenase-2 inhibitor induces apoptosis and enhances cytotoxicity of various anticancer agents in non-small cell lung cancer cell lines. Clin Cancer Res. 2000;6(5): 2006-2011.

19. Masferrer JL, Koki A, Seibert K. COX-2 inhibitors. A new class of antiangiogenic agents. Ann N Y Acad Sci. 1999;889:84-86.
20. Huang M, Stolina M, Sharma S, et al. Non-small cell lung cancer cyclooxygenase-2-dependent regulation of cytokine balance in lymphocytes and macrophages: up-regulation of interleukin 10 and down-regulation of interleukin 12 production. Cancer Res. 1998;58(6): 1208-1216.

21. Stolina M, Sharma S, Lin Y, et al. Specific inhibition of cyclooxygenase 2 restores antitumor reactivity by altering the balance of IL-10 and IL-12 synthesis. J Immunol. 2000;164(1):361-370.

22. Dohadwala M, Luo J, Zhu L, et al. Non-small cell lung cancer cyclooxygenase-2-dependent invasion is mediated by CD44. $J$ Biol Chem. 2001;276(24):20809-20812.

23. Dohadwala M, Batra RK, Luo J, et al. Autocrine/paracrine prostaglandin E2 production by non-small cell lung cancer cells regulates matrix metalloproteinase-2 and CD44 in cyclooxygenase-2-dependent invasion. J Biol Chem. 2002;277(52):50828-50833.

24. Csiki I, Morrow JD, Sandler A, et al. Targeting cyclooxygenase-2 in recurrent non-small cell lung cancer: a phase II trial of celecoxib and docetaxel. Clin Cancer Res. 2005;11(18):6634-6640.

25. Fidler MJ, Argiris A, Patel JD, et al. The potential predictive value of cyclooxygenase-2 expression and increased risk of gastrointestinal hemorrhage in advanced non-small cell lung cancer patients treated with erlotinib and celecoxib. Clin Cancer Res. 2008;14(7):2088-2094.

26. Altorki NK, Keresztes RS, Port JL, et al. Celecoxib, a selective cyclooxygenase-2 inhibitor, enhances the response to preoperative paclitaxel and carboplatin in early-stage non-small-cell lung cancer. J Clin Oncol. 2003;21(14):2645-2650.

27. Nugent FW, Mertens WC, Graziano S, et al. Docetaxel and cyclooxygenase-2 inhibition with celecoxib for advanced non-small cell lung cancer progressing after platinum-based chemotherapy: a multicenter phase II trial. Lung Cancer. 2005;48(2):267-273.

28. Lilenbaum R, Socinski MA, Altorki NK, et al. Randomized phase II trial of docetaxel/irinotecan and gemcitabine/irinotecan with or without celecoxib in the second-line treatment of non-small-cell lung cancer. J Clin Oncol. 2006;24(30):4825-4832.

29. Dai P, Li J, Ma XP, Huang J, Meng JJ, Gong P. Efficacy and safety of COX-2 inhibitors for advanced non-small-cell lung cancer with chemotherapy: a meta-analysis. Onco Targets Ther. 2018;11:721-730.

30. Moher D, Liberati A, Tetzlaff J, Altman DG; PRISMA Group. Preferred reporting items for systematic reviews and meta-analyses: the PRISMA statement. J Clin Epidemiol. 2009;62:1006-1012.

31. Higgins JP, Altman DG, Gotzsche PC, et al. The Cochrane Collaboration's tool for assessing risk of bias in randomised trials. BMJ. 2011; 343:d5928.

32. Higgins JP, Thompson SG, Deeks JJ, Altman DG. Measuring inconsistency in meta-analyses. BMJ. 2003;327(7414):557-560.

33. De Ruysscher D, Bussink J, Rodrigus P, et al. Concurrent celecoxib versus placebo in patients with stage II-III non-small cell lung cancer: a randomised phase II trial. Radiother Oncol. 2007;84(1):23-25.

34. Groen HJ, Sietsma H, Vincent A, et al. Randomized, placebo-controlled phase III study of docetaxel plus carboplatin with celecoxib and cyclooxygenase-2 expression as a biomarker for patients with advanced non-small-cell lung cancer: the NVALT-4 study. J Clin Oncol. 2011; 29(32):4320-4326.

35. Koch A, Bergman B, Holmberg E, et al. Effect of celecoxib on survival in patients with advanced non-small cell lung cancer: a double blind randomised clinical phase III trial (CYCLUS study) by the Swedish Lung Cancer Study Group. Eur J Cancer. 2011;47(10):1546-1555.

36. Reckamp KL, Koczywas M, Cristea MC, et al. Randomized phase 2 trial of erlotinib in combination with high-dose celecoxib or placebo in patients with advanced non-small cell lung cancer. Cancer. 2015; 121(18):3298-3306.

37. Edelman MJ, Wang X, Hodgson L, et al. Phase III randomized, placebo-controlled, double-blind trial of celecoxib in addition to standard chemotherapy for advanced non-small-cell lung cancer with cyclooxygenase-2 overexpression: CALGB 30801 (Alliance). J Clin Oncol. 2017;35(19):2184-2192. 
38. Sandler AB, Dubinett SM. COX-2 inhibition and lung cancer. Semin Oncol. 2004;31(2 Suppl 7):45-52.

39. Ratnasinghe D, Daschner PJ, Anver MR, et al. Cyclooxygenase-2, P-glycoprotein-170 and drug resistance; is chemoprevention against multidrug resistance possible? Anticancer Res. 2001;21(3C):2141-2147.

40. Zelenay S, van der Veen AG, Bottcher JP, et al. Cyclooxygenasedependent tumor growth through evasion of immunity. Cell. 2015; 162(6):1257-1270.

41. Masferrer JL, Leahy KM, Koki AT, et al. Antiangiogenic and antitumor activities of cyclooxygenase-2 inhibitors. Cancer Res. 2000;60(5): 1306-1311.

42. Hida T, Kozaki K, Ito H, et al. Significant growth inhibition of human lung cancer cells both in vitro and in vivo by the combined use of a selective cyclooxygenase 2 inhibitor, JTE-522, and conventional anticancer agents. Clin Cancer Res. 2002;8(7):2443-2447.

43. Mutter R, Lu B, Carbone DP, et al. A phase II study of celecoxib in combination with paclitaxel, carboplatin, and radiotherapy for patients with inoperable stage IIIA/B non-small cell lung cancer. Clin Cancer Res. 2009; 15(6):2158-2165.
44. Altorki NK, Port JL, Zhang F, et al. Chemotherapy induces the expression of cyclooxygenase-2 in non-small cell lung cancer. Clin Cancer Res. 2005;11(11):4191-4197.

45. Sorenson S, Fohlin H, Lindgren A, et al. Predictive role of plasma vascular endothelial growth factor for the effect of celecoxib in advanced non-small cell lung cancer treated with chemotherapy. Eur J Cancer. 2013;49(1):115-120.

46. Nissen SE. Cox-2 inhibitors and cardiovascular disease: considerable heat, but not much light. Eur Heart J. 2012;33(21):2631-2633.

47. Senior K. COX-2 inhibitors: cancer prevention or cardiovascular risk? Lancet Oncol. 2005;6(2):68.

48. Valcarcel M, Mendoza L, Hernandez JJ, et al. Vascular endothelial growth factor regulates melanoma cell adhesion and growth in the bone marrow microenvironment via tumor cyclooxygenase-2. J Transl Med. 2011;9:142.

49. Lorenz M, Slaughter HS, Wescott DM, et al. Cyclooxygenase-2 is essential for normal recovery from 5-fluorouracil-induced myelotoxicity in mice. Exp Hematol. 1999;27(10):1494-1502. 


\section{Supplementary materials}

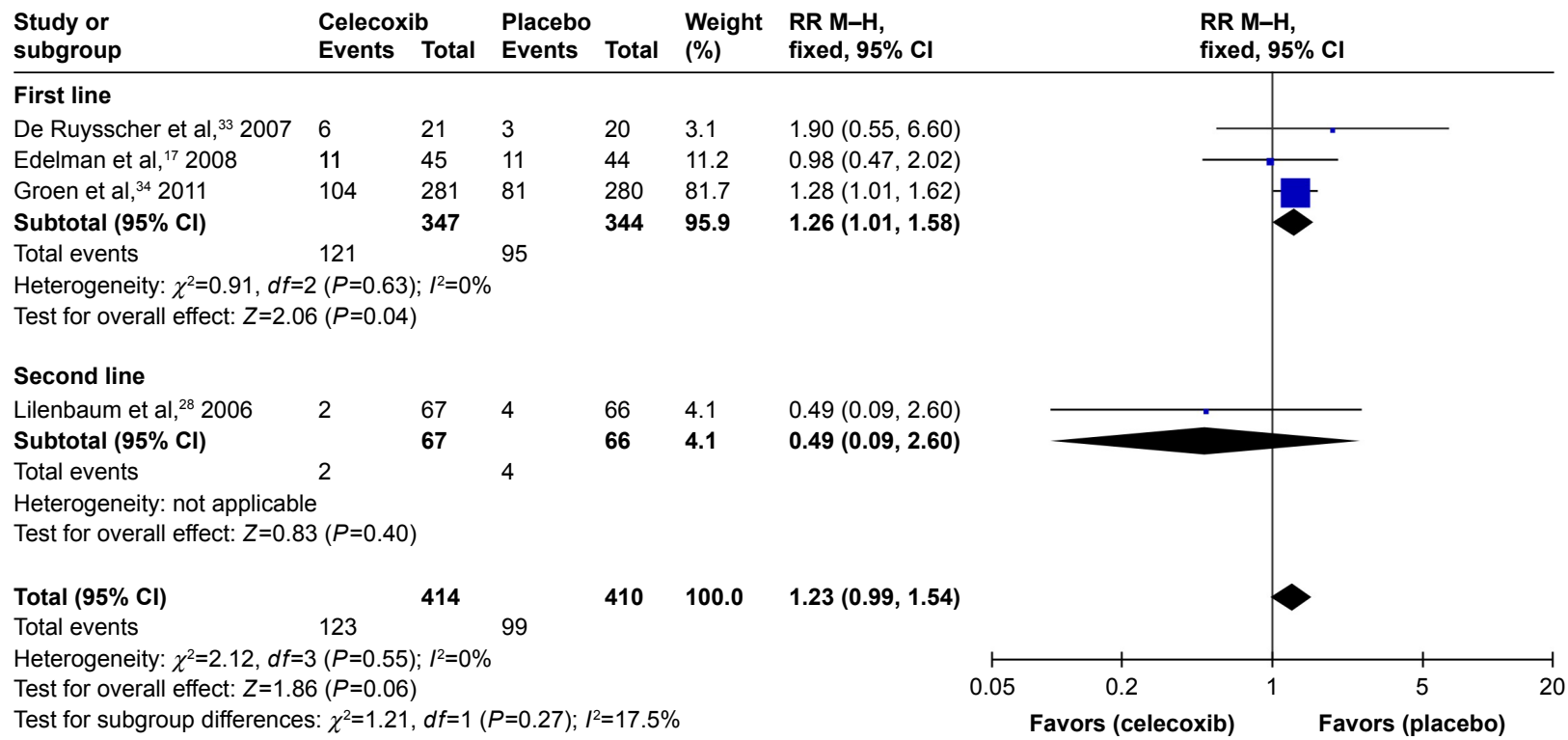

Figure SI Forest plot for subgroup analysis of the PR according to line of treatment. Abbreviations: $\mathrm{M}-\mathrm{H}$, Mantel-Haenszel; PR, partial response; RR, risk ratio.
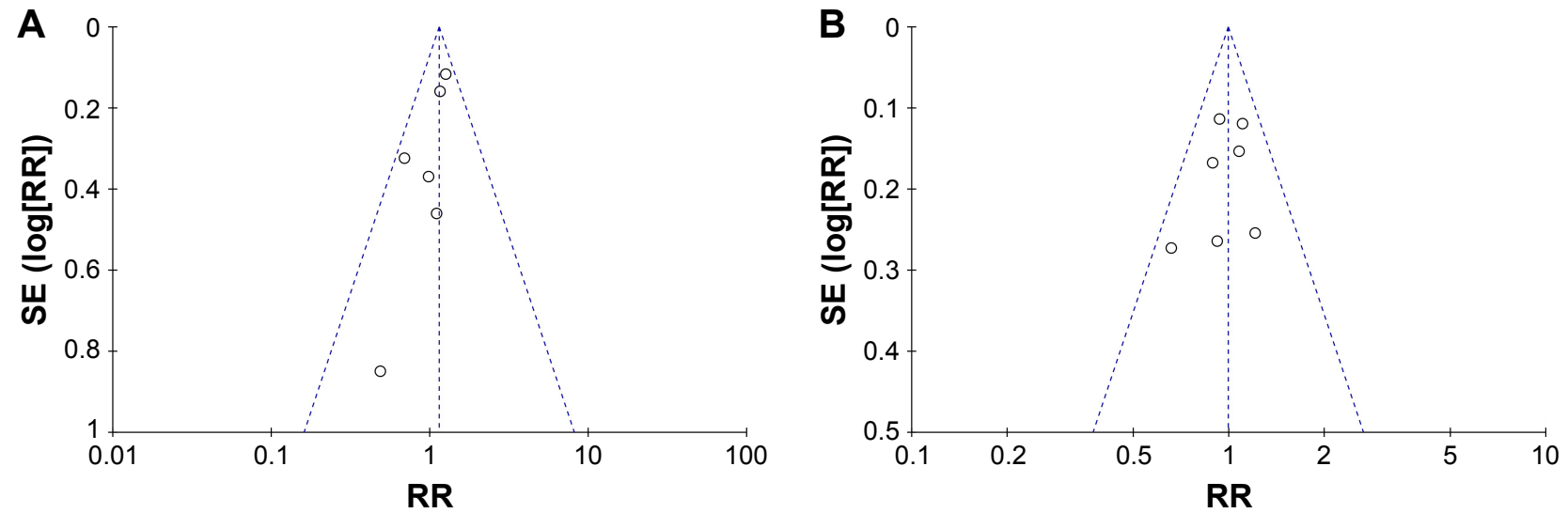

Figure S2 Funnel plot of ORR and OS-12 for studies included in the meta-analysis.

Note: (A) ORR and (B) OS-12.

Abbreviations: ORR, overall response rate; OS-12, I-year survival; RR, risk ratio; SE, standard error.

\section{Publish your work in this journal}

Drug Design, Development and Therapy is an international, peerreviewed open-access journal that spans the spectrum of drug design and development through to clinical applications. Clinical outcomes, patient safety, and programs for the development and effective, safe, and sustained use of medicines are the features of the journal, which has also been accepted for indexing on PubMed Central. The manuscript management system is completely online and includes a very quick and fair peer-review system, which is all easy to use. Visit http://www.dovepress.com/testimonials.php to read real quotes from published authors. 